\title{
ABSTRACT MATHEMATICAL MODELS USED IN COLOUR MANAGEMENT https://doi.org/10.47743/jopafl-2021-22-13
}

\author{
Gheorghe DONCEAN \\ Gheorghe Asachi Technical University, \\ Iasi, Romania \\ doncean@tex.tuiasi.ro
}

Marilena DONCEAN

Romanian Academy, Iasi branch,, “Gheorghe Zane” Institute of Economic and Social Research, Romania

doncean_m1967@yahoo.com

\author{
Alina SULENCO \\ “Alecu Russo”State University, \\ Bălți, Republic of Moldova \\ alina.suslenco@mail.ru
}

\begin{abstract}
The colour space is an abstract mathematical model showing how colours can be represented. The colour systems in use are based on CIE (International Commission on Illumination) colour coordinates (RGB, CYM, CIELab, CIELuv, CMYK) and respectively on color assessment systems (Munsell, Hunter, Pantone or Trumach). The best known colour patterns are: RGB (Red, Green, Blue), CMYK (Cyan, Mangenta, Yellow, Black), HSV (Hue, Saturation, Value), HSL (Hue, Saturation, Lightness/Luminance). Modern colour analysis covers various colour spaces, e.g. HSL, HSI, HSB, CAT02LMS, as ways in which independent and dependent representations communicate and adapt to each other, laying the bases of the specific transfer matrix equation. Colour transfer between colour reception and rendering devices is conducted based on a selected mathematical model. A comparative analysis of various spatial representations is thus provided.
\end{abstract}

Keyword: colour space, mathematical model, analysis, colorimetry, system

JEL Classification: C02, C26, C31, C51, C63

\section{Introduction}

Colour refers to the perception by the eyes of one or more frequencies (in the electromagnetic spectrum) of light. These frequencies combine in the brain and trigger the perception of colour. In reality, colour does not exist, as for each wavelength the brain arbitrarily associates one colour (Buckley et al, 2011). A sheet of paper (which reflects all spectrum colours equally) appears as white if it is illuminated by a yellow light generated by an electric light bulb. However, it will also appear white when illuminated with the white light coming from the sun. The spectral distribution of light reflected in the two cases is different. Nevertheless the perceived colour will be the same since the brain compensates for the colour of the light perceived by the eyes from the paper sheet (basically by calibration according to the colors of the ambient light). Light is a primary source of energy for the universe and is also the basic element in photography (the term "photography" 
comes from Greek and means “drawing with light”). Light, from the perspective of physics, is an electromagnetic radiation with a particular frequency. The different frequencies of light are perceived by our eyes in the form of colours.

Colour management is the set of mathematical and physical patterns that define objective colour perception and comprises measurement devices, measurement techniques and data management (Suslenco, 2015). "Color Management", expresses the concept that color descriptions dependent on equipment and editing programs in a precisely known image reproduction stream are transformed into a generic description used to control accurate color reproduction. Color management is the term used in the field of digital technology and computers to describe controlled color conversion between different color reproduction equipment such as scanners, digital cameras, TV monitors, printers, offset presses and appropriate reproduction media. Colour management involves the following steps (see examples: figure 1, figure 2):

- $\quad$ retrieving the spectral data by means of a spectro colorimeter;

- $\quad$ storing data in databases;

- $\quad$ colorimetric data processing with a specialised computing software;

- $\quad$ conducting additional instrumental analyses and inputting finding into a database;

- $\quad$ choosing the standard against which the Accept/Reject decision will apply to the quality of the product being assessed;

- $\quad$ processing the data in order to define the Accept/Reject decision criteria;

- $\quad$ classifying the analysed products based on their quality

Figure 1. Data retrieval system

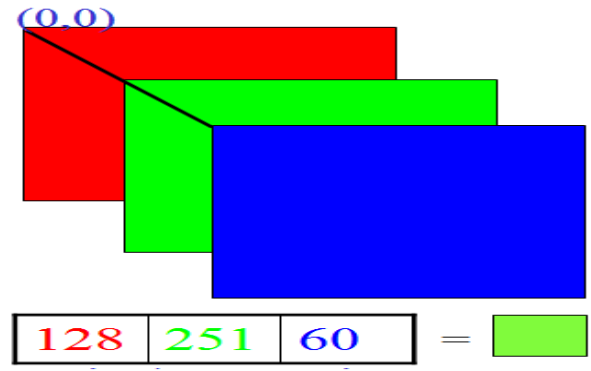

Source: Boyer and Morales, 2008, p.23
Figure 2. RGB matrix coding of a pixel

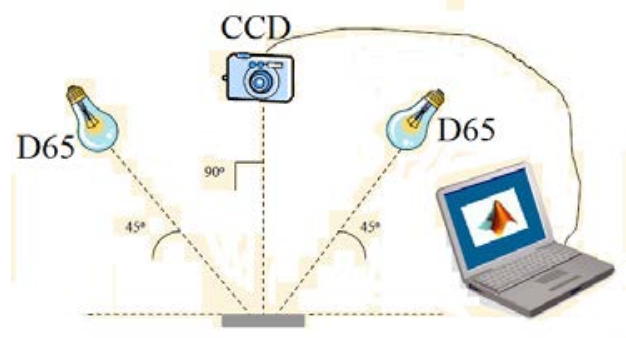

Source: Boyer and Morales, 2008, p.25

The linear and uniform RGB colour space can includeup to 255 x 255 × $255=$ $16,581,375$ colours, far exceeding the capabilities of the human eye in the $400-700 \mathrm{~nm}$ wavelength interval. In colour rendering technique, each pixel contains information about the trichromatic components red, green and blue, specific to additive mixes, in [r g b] form with each component value ranging between 0 and 255 or in standard form, in which case the colour cube faces are even. From the standpoint of the colour designer, any random colour can be characterised by hue, lightness and, saturation. The interpretation of the values of these basic features by digital image analysis is important in industrial practice for correcting printed designs and also for the technological analysis of print quality. The colour management system manages how each device involved in retrieving or displaying images reads, interprets and displays each particular colour. The world is becoming increasingly complex, therefore ever more simple solutions are required in all fields, 
including the media and printing and publishing industries. At a technical level, colour must be correct and accurate, to the extent allowed by current technology and must comply with the rules of optics. It should be possible to carry and transfer colour between the devices and software that process it to produce colour reproductions identical with the originals so far as possible: nature images, photographs, the works of visual artists, (Doncean and Doncean, 2012, p.76).

\section{Research methodology. Classical colour spaces}

Defining the colour space is the key to success for any colour management system. The latter is more effective if, instead of an ad hoc conversion between any potential combination of input and output devices, it defines a reference colour space that expresses both the colorimetry of the reference environment and the viewing conditions it assumes. The colour spaces used in image analysis are categorised into four families (Doncean and Doncean, 2012, p.189):

1. Primary spaces based on trichromatic theory, i.e. each colour can be obtained by mixing three primary colours;

2. Spaces based on luminosity and two-component chromaticity;

3.Perceptual spaces attempting to quantify man's subjective colour perception, based on intensity, hue and saturation components.

4. Independent spaces based on the statistical methods of correlating the coloristic quantities being analysed.

\section{Perception spaces}

Perception spaces create the link between man and the colour rendering devices for description purposes. Such spaces include HSI, HSB, HSL, HSV, CHL, SHL, etc. each with specific components. The dimensions to be analysed can be represented in polar (or cylindrical) coordinates through I, B, L, V and the two chromaticity components $\mathrm{H}$ and S, $\mathrm{C}$ and H., see in figures 3, 4, 5, 6 (Doncean and Doncean, 2012).

Figure 3.Cylindric perception spaces LCH space

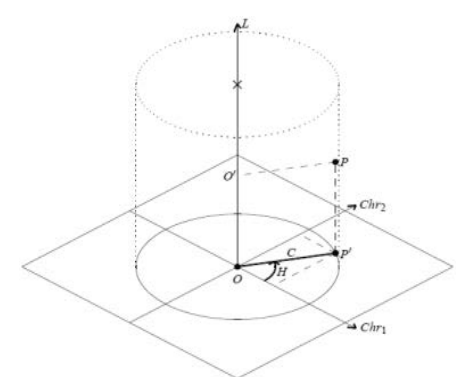

Source: Wang and Mueller, 2008, p.218

Figure 5. Hexacon perception space space LSH space
Figure 4. Triangular perception space in the RGB cube. RGB - CMY complex space

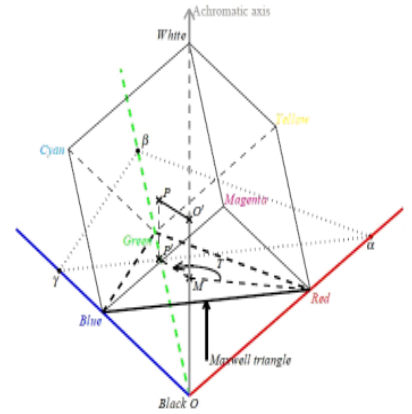

Source: Wang and Mueller, 2008, p.218

Figure 6. Double hexagon perception space. VSH 


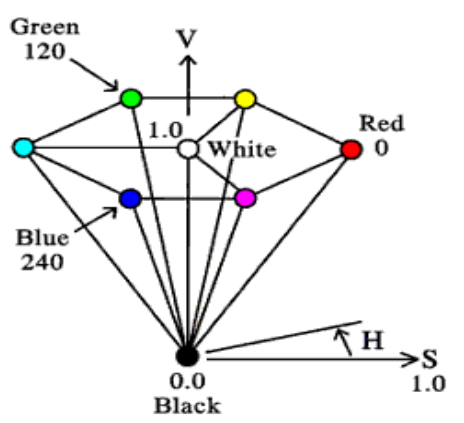

Source: Wang and Mueller, 2008, p.219

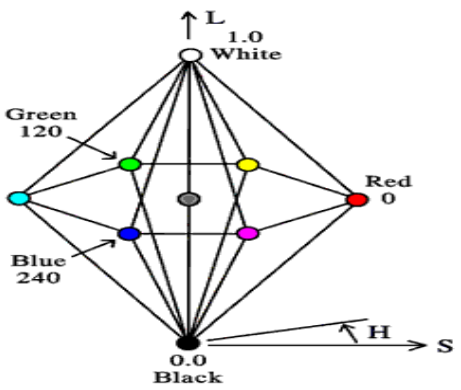

Source: Wang and Mueller, 2008, p.219

\section{Representative models based on hue and saturation}

Colour features hue $-\mathrm{H}$, saturation $-\mathrm{S}$, lightness $-\mathrm{L}$, brightness $-\mathrm{B}$, intensity $-\mathrm{I}$ or value - V can be combined in threes to represent the so-called "humanistic space spaces". HSL, HSV, HSI, HSB spaces are frequently used.

Figure 7. HSL and HSV spaces

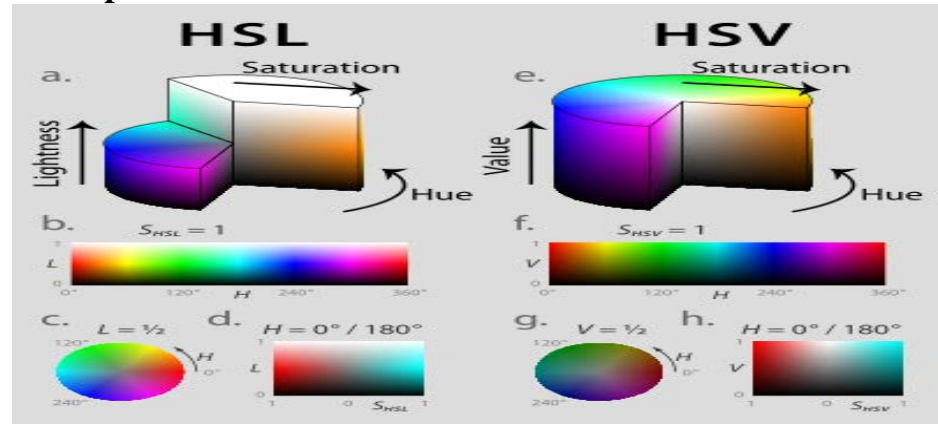

Source: Kuehni, 2003, p.89

\subsection{HSV colour space}

The HSV colour space is suitable for dependent or independent representations. The HSV space is related to the s RGB space, as a derivative. The HSV space appears as a hexagonal pyramid where:

$$
\begin{gathered}
0<=\mathrm{H}<360 \text {, saturation with dominant wavelength, } \\
0<-\mathrm{S}<-1 \text {, white content, } \\
0,=\mathrm{V}<=1 \text {, black content, } \\
\text { where: } \\
\mathrm{S}=\mathrm{C} / \mathrm{V}, \\
\mathrm{V}=\max \left(\mathrm{R}^{\prime}, \mathrm{G}^{\prime}, \mathrm{B}^{\prime}\right)-\min \left(\mathrm{R}^{\prime}, \mathrm{G}^{\prime}, \mathrm{B}^{\prime}\right) .
\end{gathered}
$$


Figure 8. HSV space

H

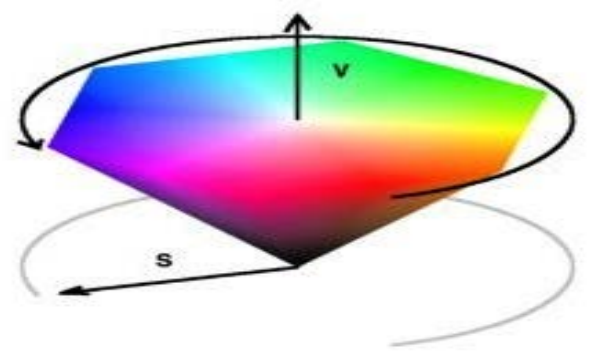

Source: Klanjšek, 2010, p.34

The HSV colour space is suitable for dependent or independent representations. The HSV space is related to the s RGB space, as a derivative. The HSV space appears as a hexagonal pyramid in which:

$$
\begin{gathered}
0<=\mathrm{H}<360 \text {, saturation with dominant wavelength, } \\
0<-\mathrm{S}<-1 \text {, white content, } \\
0,=\mathrm{V}<=1 \text {, black content, } \\
\text { where: } \mathrm{S}=\mathrm{C} / \mathrm{V} \text {, } \\
\mathrm{V}=\max \left(\mathrm{R}^{\prime}, \mathrm{G}^{\prime}, \mathrm{B}^{\prime}\right)-\min \left(\mathrm{R}^{\prime}, \mathrm{G}^{\prime}, \mathrm{B}^{\prime}\right) .
\end{gathered}
$$

For 8-bit and 16-bit images, R, G and B values between 0 and 255 are normalised within the $(0,1)$ range.

$$
\begin{aligned}
& V=\max (R, G, B) \\
& S=\left\{\begin{array}{ccc}
\frac{V-\min (R, G, B)}{V} & \text { if } & V \neq 0 \\
0 & \text { if } & V=0
\end{array}\right. \\
& H=\left\{\begin{array}{ccc}
60 \cdot \frac{(G-B)}{S} & \text { if } & V=R \\
120+60 \cdot \frac{(B-R)}{S} & \text { if } & V=G \\
240+60 \cdot \frac{(R-G)}{S} & \text { if } & V=B
\end{array}\right. \\
& H=H+360 \text { if } \quad H<0 \\
& 0 \leq V \leq 1.0 \\
& 0 \leq S \leq 1 \\
& 0 \leq H \leq 360
\end{aligned}
$$

4.2. HSL colour space

Figure 9. Colours distinguished by $\mathrm{H}, \mathrm{S}$, L values
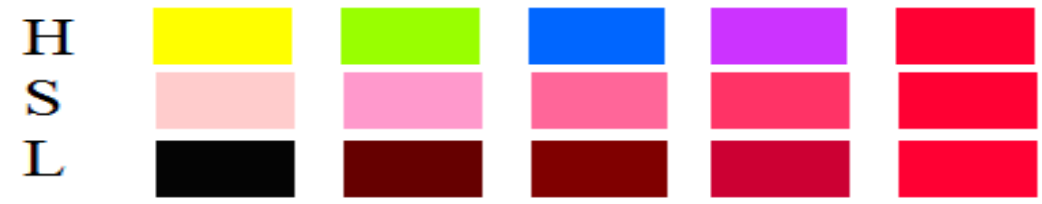

Source: Koenderink, 2010, p.101

$\mathrm{L}$ is the vertical component of the glow. The HSL model is similar to HSV. 


$$
\begin{gathered}
\text { H- angle on the hexagonal base, } 0<=\mathrm{H}<360 \text { ș } \\
\mathrm{S}=\mathrm{C} /(1-|2 \mathrm{~L}-1|),(0<=\mathrm{S}<=1), \\
\mathrm{L}=\left(\max \left(\mathrm{R}^{\prime}, \mathrm{G}^{\prime}, \mathrm{B}^{\prime}\right)+\min \left(\mathrm{R}^{\prime}, \mathrm{G}^{\prime}, \mathrm{B}^{\prime}\right)\right) / 2(0<=\mathrm{L}<=1),
\end{gathered}
$$

$\mathrm{H}$ and $\mathrm{C}$ are identical to those in the HSV space.

From the geometrical point of view, the space is a double cone with a hexagonal base.

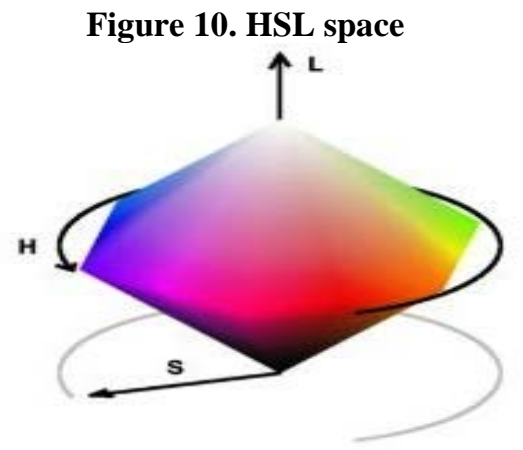

Source: Klanjšek, 2010, p.34

For 8-bit and 16-bit images, R, G and B values between 0 and 255 are normalised within the $(0,1)$ range.

$$
\begin{aligned}
& V_{\text {max }}=\max (R, G, B) \\
& V_{\text {min }}=\min (R, G, B) \\
& L=\frac{V_{\max }+V_{\min }}{2} \\
& S=\left\{\begin{array}{ccc}
\frac{V_{\max }-V_{\min }}{V_{\text {max }}+V_{\min }} & \text { if } & L<0.5 \\
\frac{V_{\text {max }}-V_{\min }}{2-\left(V_{\max }+V_{\min }\right)} & \text { if } & L \geq 0.5
\end{array}\right. \\
& H=\left\{\begin{array}{clc}
60 \cdot \frac{(G-B)}{S} & \text { if } & V_{\text {max }}=R \\
120+60 \cdot \frac{(B-R)}{S} \text { if } & V_{\text {max }}=G \\
240+60 \cdot \frac{(R-G)}{S} \text { if } & V_{\text {max }}=B
\end{array}\right. \\
& H=H+360 \quad \text { if } \quad H<0 \\
& 0 \leq L \leq 1.0 \\
& 0 \leq S \leq 1 \\
& 0 \leq H \leq 360
\end{aligned}
$$

The reverse conversion involves:

- for the 8-bit image: 


$$
\begin{aligned}
& \boldsymbol{V}=255 \cdot \boldsymbol{V} \\
& \boldsymbol{S}=255 \cdot \boldsymbol{S} \\
& \boldsymbol{H}=\frac{\boldsymbol{H}}{2}
\end{aligned}
$$

In HSV and HSL spaces the saturation angle is computed for the circle that includes the hexagonal base.

\section{HSI colour space}

HSI (Hue - Saturation - Intensity) is derived from the sRGB space.

$\mathrm{H}-$ polar angle of hue, $(0<=\mathrm{H}<360)$,

$$
\left.\mathrm{S}=1-\min \left(\mathrm{R}^{\prime}, \mathrm{G}^{\prime}, \mathrm{B}^{\prime}\right) / \mathrm{I}, 0<=\mathrm{S}<=1\right) \text {, }
$$

$$
\left.\mathrm{I}=\left(\mathrm{R}^{\prime}+\mathrm{G}^{\prime}+\mathrm{B}^{\prime}\right) / 3,0<=\mathrm{I}<=1\right) \text {. }
$$

\section{Results. Conversion formulae: RGB to HSI conversion}

Normalising RGB values.

$$
\begin{aligned}
& r=\frac{R}{R+G+B} \\
& g=\frac{G}{R+G+B} \\
& b=\frac{B}{R+G+B}
\end{aligned}
$$

Computing the normalised components of H,S,I values:

$$
\begin{gathered}
h=\cos ^{-1}\left\{\frac{0,5 \cdot[(r-g)+(r-b)]}{\left[\left((r-g)^{2}+(r-b) \cdot(g-b)\right)^{\gamma}\right.}\right\}, \\
h \in[0, \pi], b \leq g ; \\
h=2 \cdot \pi-\cos ^{-1}\left\{\frac{0,5 \cdot[(r-g)+(r-b)]}{\left[(r-g)^{2}+(r-b) \cdot(g-b)\right]}\right\}, \\
h \in[\pi, 2 \cdot \pi], b>g . \\
\quad s=1-3 \cdot \min (r, g, b) ; s \in[0,1] ; \\
\quad i=(R+G+B) /(3 \cdot 255) ; i \in[0,1] .
\end{gathered}
$$

Converting h, s, i values to the corresponding ranges: [0,360], [0,100], [0,255]:

$$
\begin{aligned}
& H=h \cdot \frac{180}{\pi} ; \\
& S=s \cdot 100 \\
& I=i \cdot 255
\end{aligned}
$$

\section{Calculation model in HSI to RGB conversion}




$$
\begin{aligned}
& h=H \cdot \frac{\pi}{180} ; s=S / 100 ; i=I / 255 ; \\
& x=i \cdot(1-s) ; \\
& y=i \cdot\left[1+\frac{s \cdot \cos (h)}{\cos \left(\frac{\pi}{3}-h\right)}\right] \cdot \\
& h<\frac{2 \cdot \pi}{3}, \quad b=x, \quad \gamma=y, \quad g=z ; \\
& \frac{2 \cdot \pi}{3} \leq h \leq \frac{4 \cdot \pi}{3}, h=h-\frac{2 \cdot \pi}{3}, \\
& \gamma=x, \quad g=y \quad b=z ; \\
& \frac{4 \cdot \pi}{3} \leq h<2 \cdot \pi, h=h-\frac{4 \cdot \pi}{3} \\
& g=x, \quad b=y, \quad \gamma=z .
\end{aligned}
$$

The normalised $\mathrm{r}$, g, b values in the $[0,1]$ range are multiplied by 255 when presented (see Table 1)

Table.1 Example:

\begin{tabular}{|c|c|c|}
\hline$(100,100,100)$ & $(150,0,0)$ & $(0,150,0)$ \\
\hline$(255,0,0)$ & $(255,255,255)$ & $(0,0,0)$ \\
\hline$(100,150,100)$ & $(0,0,255)$ & $(100,150,200)$ \\
\hline
\end{tabular}

Source: Data processed by the authors

\section{Calculation model in RGB to HSI conversion}

For the $(100,200,150)$ pixel the following calculation is performed:

$$
\begin{aligned}
& r=\frac{R}{R+G+B}=\frac{100}{450}=0,222 \\
& g=\frac{G}{R+G+B}=\frac{150}{450}=0,333 \\
& b=\frac{B}{R+G+B}=\frac{200}{450}=0,444 \\
& r+g+b=1
\end{aligned}
$$




$$
\begin{aligned}
& b=0,44>g=0,33 ; \\
& h=2 \cdot \pi-\cos ^{-1}\left\{\frac{0,5 \cdot[(r-g)+(r-b)]}{\left[(r-g)^{2}+(r-b) \cdot(g-b)\right]}\right\}= \\
& =1,167 \cdot \pi, \\
& s=1-3 \cdot \min (r, g, b)=0,333 ; \\
& H=h \cdot \frac{180}{\pi}=210, \\
& S=s \cdot 100=33,3, \\
& I=\frac{(R+G+B)}{3}=150 .
\end{aligned}
$$

\section{Calculation model in HSI to RGB conversion}

$$
\begin{aligned}
& h=H \cdot \frac{\pi}{180}=\frac{7 \cdot \pi}{6} \\
& s=\frac{S}{100}=0,333 \\
& i=\frac{I}{255}=0.588
\end{aligned}
$$

Because:

$$
\begin{gathered}
\frac{2 \cdot \pi}{3} \leq h \leq \frac{4 \cdot \pi}{3}, \\
h=h-\frac{2 \cdot \pi}{3}=\frac{\pi}{2}, \\
\gamma=x=i \cdot(1-s)=0,392 ; \\
g=y=i \cdot\left[1+\frac{s \cdot \cos (h)}{\cos \left(\frac{\pi}{3}-h\right)}\right]=0,588 ; \\
b=z=3 \cdot i-(x+y) . \\
R=255 \cdot r=100 ; \\
G=255 \cdot g=150 ; \\
B=255 \cdot b=200 .
\end{gathered}
$$




\section{EXPERIMENTAL PART}

a) CIE colour spaces.

Figure 11. RGB study image.

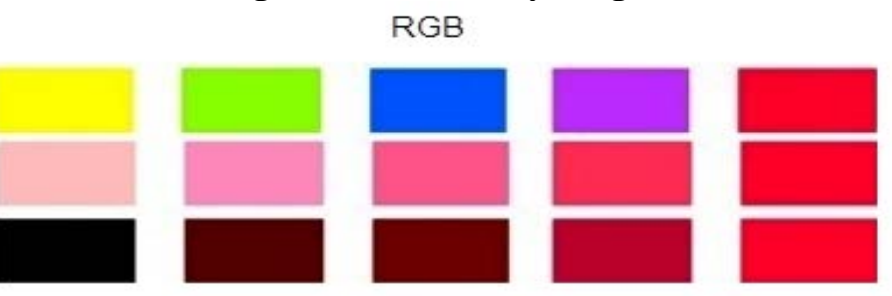

Source: Data processed by the authors

Figure 12. Representations in CIE spaces

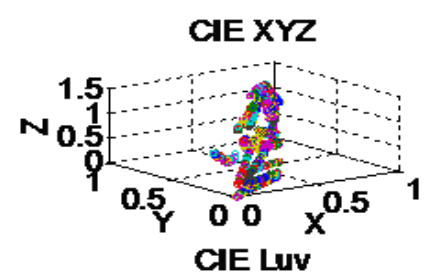

CIE Lab
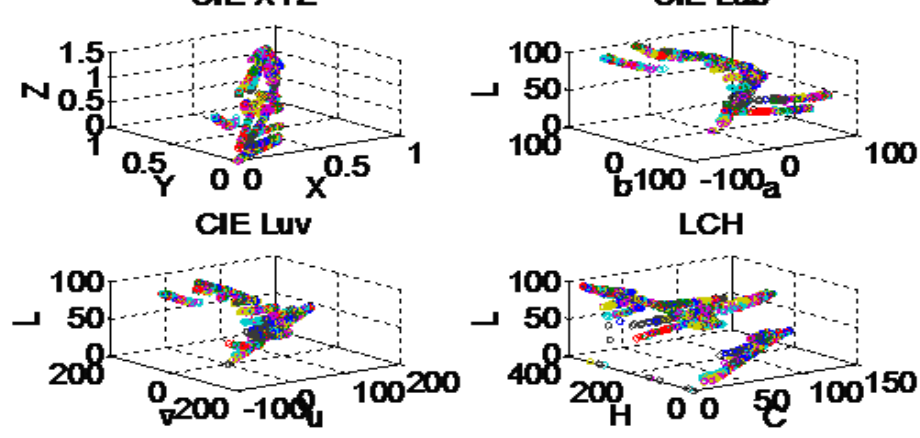

Source: Data processed by the authors

Figure 13. Locus CIE xy

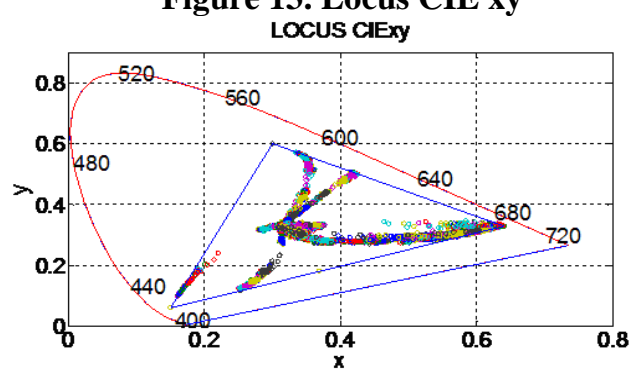

Source: Data processed by the authors
Figure 14. Locus CIE u'v'

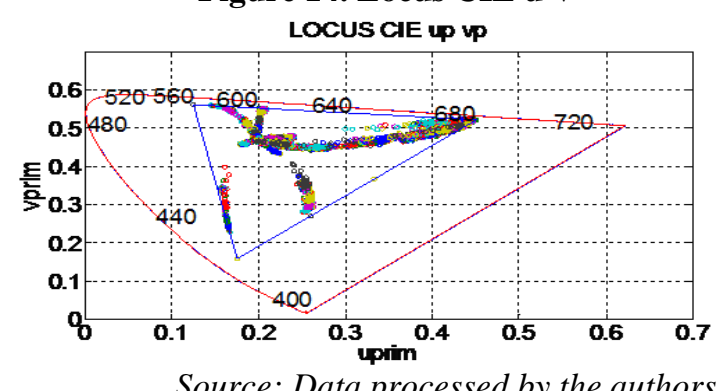




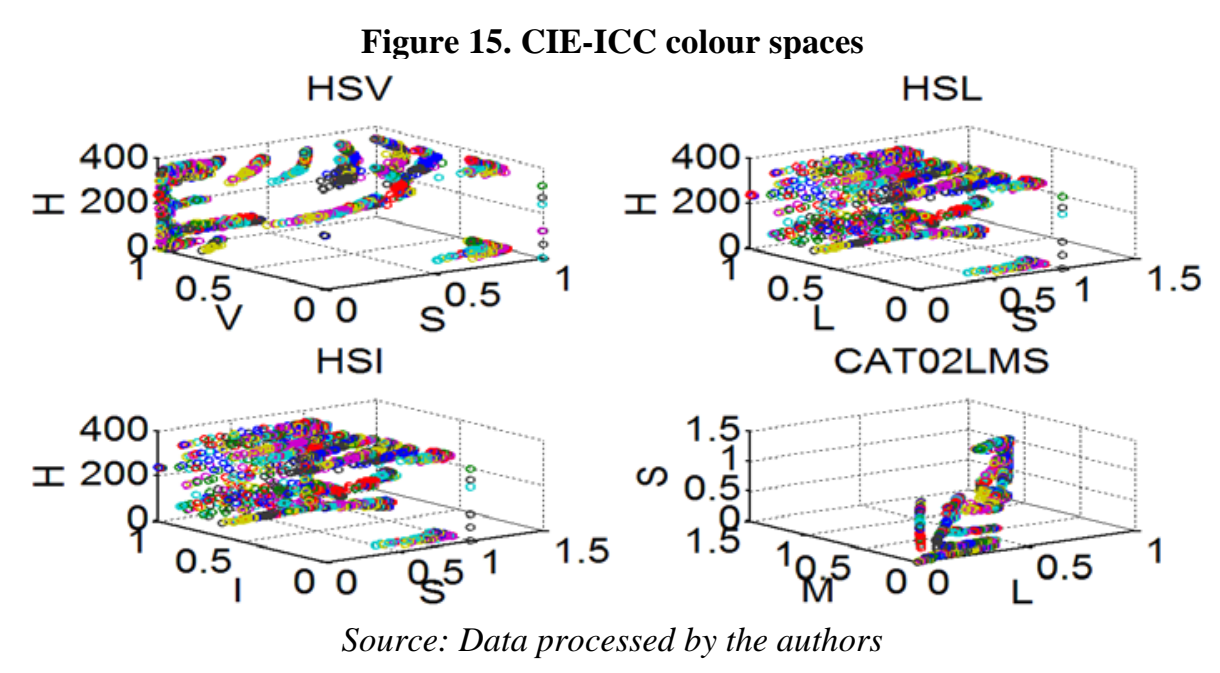

Figure 16. CIE-ICC representations

HSV

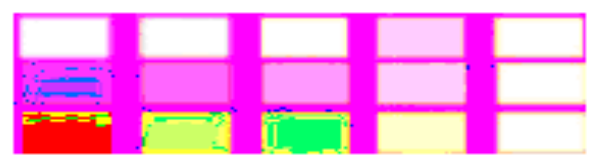

HST

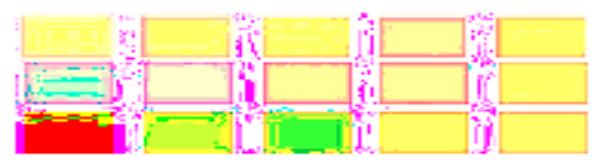

HSL

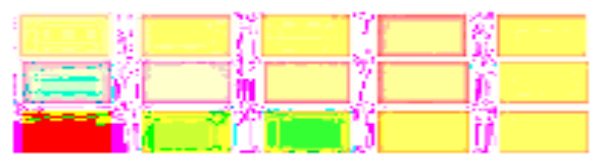

CATIZMUS

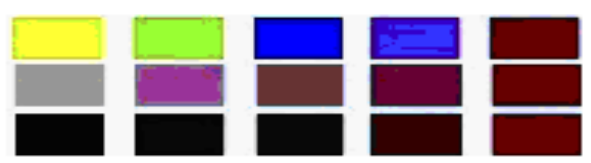

Source: Data processed by the authors

\section{Conclusions}

Reproducing colour images, if not identical, almost identical to the original images, requires knowledge of colour management as a science and its application throughout the workflow. For these purposes, experts in the field need to understand both colour reproduction processes and how devices and image editing software operate and describe colour. They also need to understand the nature and behaviour of the various colour reproduction media and colour spaces. Therefore, it is particularly important and necessary to be familiar with among others: the concept of light and the basic theory of colour, how colour is perceived by the human vision system and the complex factors that affect it, the way in which colours are described (representation or specification) and measured, the complexity of colour image reproduction. Last but not least, they need to know, at the conceptual level, the components of a colour management system and their operation as a whole, to achieve the stated goal, namely: obtaining real colour images using digital technology. The printing and publishing industry, graphic art and multimedia communication are the main beneficiaries of colour management. In today's global society colour management systems offer major advantages, such as the ability to communicate, 
despite geographic barriers, information from any field, expressed in complex colour images, ever more suggestive and easy to understand.

\section{References}

1. Boyer, E and Morales, A. (2008), Color image merging algorithm using Matlab, Proceedings of the 2008 ASEE Annual Conference, June 22 - 25,Pittsburgh, pp.23-25

2. Buckley, R., Puglia, S., Stelmach, M., Wheeler, F. B., and He, L.(2011), Recent work on archival color spaces, University of Connecticut, USA

3. Christie, R, Robertson, S and Taylor S., Design concepts for a temperature sensitive environment using therochromic colour change, Colour: Design\&Creativity, no. 1 -5, pg. 1 - 11 School of Textile\$Design, Heriot Watt, University, UK

4. Doncean G. and Doncean M. (2012), Modelarea, simularea şi optimizarea proceselor tehnologice, Editura Performantica, Iaşi, p.76

5. Doncean G. and Doncean M. (2016), Ingineria creativitatii tehnice, Editura Tehnopress, Iaşi

6. Doncean G. and Doncean M. (2012), Mapping the colour gamut of works of art.Chromatic diagram, Inventica, Editura Performantica Iași, pp. 179-188.

7. Doncean G. and Doncean M. (2012), Mapping the colour gamut of works of art.Colour spaces, Inventica, Editura Performantica Iași, pp. 189-194

8. Klanjšek M. G. (2010), Dynamic Colour of chromogenic materials, IX Congreso Nacional del color, Alicante, p.34

9. Kuehni R. G. (2003), Color Space and Its Divisions. Color Order from Antiquity to the Present, Wiley -Interscience, p.89

10. Koenderink, J. J. (2010), Color for the Sciences, MIT press, Cambridge, Massachusset, p.101.

11. McNames, J. (2006), An effective color scale for simultaneous color and gray scale publications,

IEEE Signal Processing Magazine, Volume 23, Issue1, retrieved from http://bsp.pdx.edu/Publications/2006/SPM_McNames.pdf

12. Petruševski,V. and Bukleski (2008), The economic demonstrator: Prepare It once,use it many times. Phenomena of discontinuous thermochromism, Chemistry,Vol.17, Iss. 2, University, Skopje, Macedonia

13. Rogowitz, B.E.and Kalvin, A.D. (2006), Why Should Engineers and Scientists Be Worried About Color? retrieved from http://www.research.ibm.com/people/l/lloydt/color/color.HTM

14. Rogowitz, B.E. and Kalvin, A.D. (2007, How NOT to Lie with Visualization, retrieved from http://www.research.ibm.com/dx/proceedings/pravda/truevis.htm

Wang, L. and Mueller, K, (2008), Color maps for Volume Visualization, IEEE/ EG Symposium on Volume and Point-Based Graphics, pp.218,21

15. Suslenco Alina, Modelarea relațiilor dintre competitivitate și capital uman. In: Revista „Economica”, 2015, nr.3 (93), Chișinău, ASEM, p.14-20 . ISSN 1810-9136 (0.36 c.a.). Disponibil: http://irek.ase.md/xmlui/bitstream/handle/123456789/189/SuslencoA_ec_2015_3.pdf?sequence=1\&isAllo wed=y 